\title{
MARKETING COMMUNICATION MODEL FOR SOCIAL NETWORKS
}

\author{
Martin KLEPEK (D) ${ }^{*}$, Halina STARZYCZNÁ2 \\ 1, 2 Department of Business Economics and Management, \\ School of Business Administration in Karviná, Silesian University in Opava, Czech Republic
}

Received 21 June 2018; accepted 09 October 2018

\begin{abstract}
The advent of social media offers yet another set of communication channels which can brand add to integrated marketing communication strategies. Contrary to online advertising available on social media where traditional advertising logic provides an adequate explanation, the content creation and dialogue on social networks still lack sufficient understanding. Consequently, there are many companies which tend to misunderstand customers communication needs within the social media landscape. The obvious reason is the lack of knowledge combined with resistance to change. To bridge this gap, there is a need for empirical research which will clarify the current communication needs of customers. To explore this phenomenon, exploratory research employing questionnaire involving 481 respondents was evaluated with factor analysis method. Identification of three factors provided deeper insights into the understanding of attitudes and behaviour of the current internet population in the Czech Republic. Social network Facebook was chosen as the most widespread not only locally but also globally. Based on this research and previous research studies on communication, a new communication model is proposed in which the element of interaction is the most important. The proposed scheme bears some novel aspects. Firstly, the content in our model is not created outside as in previous models. A social network itself provides a platform for content creation. Secondly, we expanded the physical technical environment of the social network by the abstract brand community in which not only customers but the employees form a vital part. Lastly, the data plays an important role as a valuable tool for feedback and further analysis. Data flow from customer to company enables managers to execute true mass individualisation.
\end{abstract}

Keywords: communication model, engagement, Facebook, marketing communication, social networks, social media.

JEL Classification: M31.

\section{Introduction}

The pace at which technology evolves is incomparable with any previous years. The number of people connected to the internet is increasing as well as the usage of internet based services

${ }^{\star}$ Corresponding author. E-mail: klepek@opf.slu.cz 
such as e-mail, social media, instant messaging, cloud computing and many others. The communication possibilities have expanded accordingly. These changes have affected virtually all industries in the private and public sector. Main shift is in the ways the companies approach the consumers. It is no more only one-way promotion as we know it from classic marketing texts. Instead, the two-way communication is in the place with all its advantages and disadvantages. The visibility of the company is only the first prerequisite. In the interconnected world, the companies' ability to build trust and relationships is essential more than ever before.

Communication through new technology brings new options for customers. The Web 2.0 provided users with the ultimate possibility to create content. Later, Social media connected various users around this content and allowed customers to share experiences with products and brands. In such an open and dynamic environment, effective marketing communication is crucial since it is an important instrument for achieving organisational goals. However, the challenge faced by many companies is in understanding ever-evolving communication shifts.

From the company's perspective, the need to communicate in accordance with consumers' standards is fundamental. In the highly competitive markets, where products can be easily copied and substituted it is important to have the opportunity to talk and listen at the same time. Adoption of these internet based communication platforms is obviously decisive from a strategic perspective. Yet many managers still struggle with the mind-set switch from the one-way communication to a communication where consumers have significantly higher power than ever. This many-to-many scheme provides a better understanding of today's world.

As social media continue to gain popularity, marketers are searching for strategies and tactics how to implement social media into marketing communication processes. New communication models, which take interactivity into account, are well-known from the literature. However, the applicability of these models is limited by its overarching nature. Business owners or managers are then sceptical and left with no solid scheme for practical marketing communication management. The aim of this paper is therefore to develop an updated marketing communication model geared on social networking sites based not only on the theoretical debate but also on empirical data from the customer's attitude measurement. To reach this objective, a literature review on communication models and survey research strategy were employed.

The paper is structured as follows. In the first chapter, we have reviewed the literature on communication models, social media, social networks and user engagement. The second part refers to the methods followed by the third part including results. The fourth part synthesises previous parts in discussions and model development. The paper ends with conclusions and research limitations.

\section{Literature review}

Paradigms that dominate and significantly affect overall discourse are linked to the development of every discipline. This paper approaches the research problem with a revolutionary marketing logic by Vargo and Lusch (2004) described as a service-dominant logic (S-D logic). 
This paradigm is based on criticism of marketing mix (Alder, 2001) and builds on relationship marketing and marketing of services (Grönroos, 1994). Vargo and Lusch (2004) indicated the consequences of the S-D logic for communication. They concluded that marketers should develop permanent communication processes with micro markets and ideally with individuals. Social networking sites allow this kind of relationships by its nature. Therefore, the S-D logic provides grounding for this paper in the process of the critical literature review. Its main objective is to connect literature on communication models with current research on social networking sites.

The term social media marketing is commonly used in business practice. Within its range, we can include blogs, social networks and online communities as the tools to be utilised to build relationships with customers. However, the term marketing is much broader, richer and complex. It is far more elaborate than communication or relationship building solely. Bringing social media marketing into a game, consequent theoretical and definition issues are appearing. It would be irresponsible to dive into the topic of social media marketing without bringing up a terminological issue, which stems from the misuse of the word marketing in general business practice.

\subsection{Communication models in online environment}

For All communication theories are still to some extent alive and exert an influence. However, mathematical one developed by Shannon (1948) is found to be the most influential yet very controversial to use in marketing. Albeit the author posed it as communication theory, it is, in fact, a mathematical representation of an information transition between sender and receiver through the medium. From a marketing perspective, the model does not describe a whole story. The core of marketing communication is a transition of meaning and not only information. Accordingly, marketing communication should focus more on the receivers and the meaning created by the receiver in the communication process (Finne \& Grönroos, 2009). Nevertheless, an invaluable contribution of Shannon's model lies in the description of mediation of communication on which the consequent computer-mediated communication (CMC) is based.

Similarly to mechanistic Shannon's model, the linear depiction also occurs in the mass communication model. Communication is seen as a process where the company transmits content over the medium to end consumers without any interaction (Figure 1). As a result, marketing managers saw the customer primarily as a passive recipient of messages (Perreault, Cannon, \& McCarthy, 2010, p. 333). Among the critics of this idea of a passive and helpless recipient is Varey (2002), who describes it as one of the major error in marketing literature. Due to developments in current communication practice, its criticism appears to be well founded and this model of mass communication is rightly considered outdated.

There are, however, authors who have become aware of its obsolescence and have tried to make the model reflecting the changing technological and media reality, and therefore better serve its purpose. As a result, a model of interpersonal communication between consumers via computer technology was developed (Figure 2). In this scheme, consumers are enabled to create content thanks to the Web 2.0 technology. From the static receivers, consumers 
become active empowered users. In this environment, communicator's strength is more evenly routed and CMC interaction has the capability to democratize communication (Kiesler, Siegel, \& Mcguire, 1984).

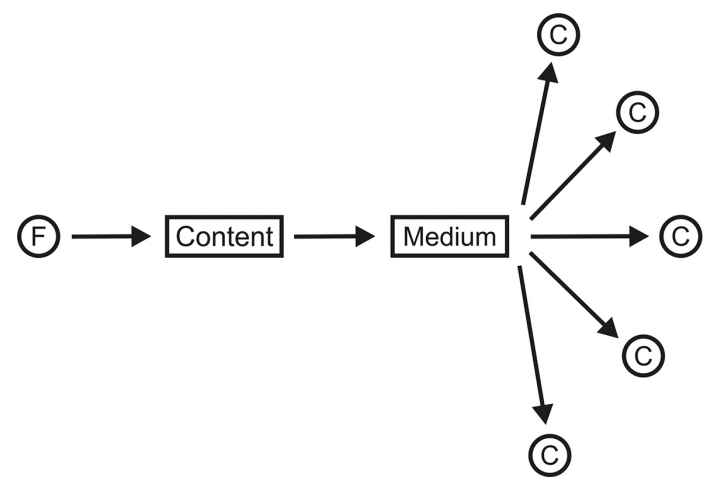

Figure 1. Traditional one-to-many model of mass communication (source: Hoffman \& Novak, 1996)

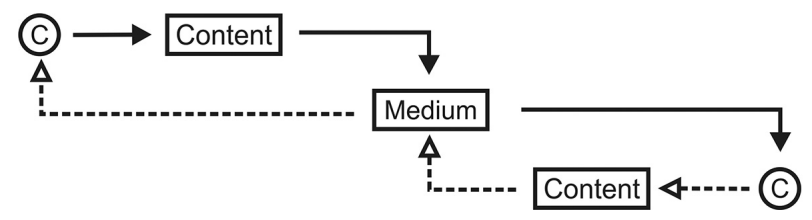

Figure 2. Model of interpersonal computer-mediated communication (source: Hoffman \& Novak, 1996)

By integration of one-to-many and computer-mediated communication a many-to-many model is developed and presented by Hoffman and Novak (1996) in their model of marketing communication in hypermedia transmitted by computer technology (Figure 3). Consumers and business have the ability to interact directly with the media, such as viewing websites (direct linking of the subject with the media), companies can also produce content (web presentation), but the most significant difference from previous models is the fact that the content created by customers is also available for other customers and companies. Pavlíček (2010, p. 94) adds that many-to-many communication allows mass individualization, a phenomenon that makes it possible to reach the mass audience while keeping an individual approach.

In the initial phase, this new form of communication did not meet the positive acceptance of a number of authors. Computing technology, according to some of them, restricts communication in smaller groups (Hiltz, Johnson, \& Turoff, 1986) and is less productive than face-to-face communication (Kiesler \& Sproull, 1992). It is clear that the main disadvantage is the absence of personal contact, which reduces the possibility of finding common elements such as gender, age, ethnicity, social or professional status, that support the formation 


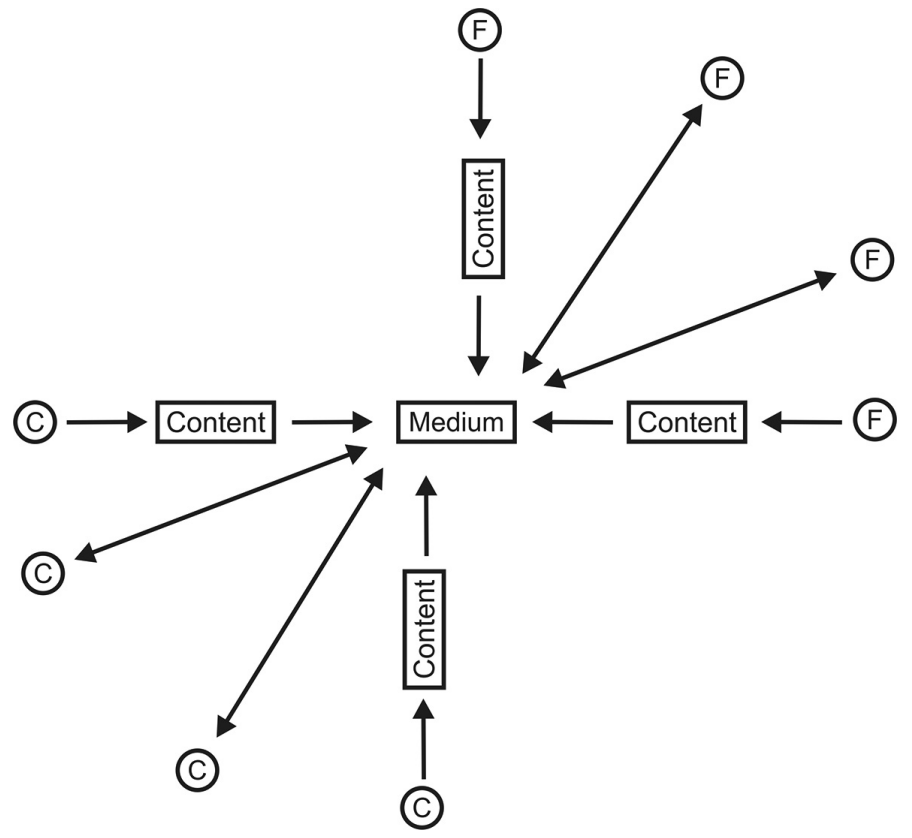

Figure 3. Model of marketing communications in a hypermedia computer-mediated environments (source: Hoffman \& Novak, 1996)

of relationships (Brown, Broderick, \& Lee, 2007). Without nonverbal tools, a sender cannot easily alter the mood of a message, communicate a sense of individuality or exercise dominance or charisma (Kiesler, 1986). However, these views are not consistent with possibilities of current technology and internet developments.

Status of anonymity has, in fact, dramatically changed with the advent of social media. Today, if the social network user wants, it is possible not only to see the demographics of the counterparts, but also the activities they are dedicated to, where they live and work, who their friends are and where they spent the last vacation. This personal data is not intended to limit the relationship formation, as indicated in initial studies, but rather encourage it. The individual participants in the communication process have the opportunity to assess a range of information about their counterpart, including his or her membership in a particular social group. All of that within a few seconds or couple of clicks. Additionally, as there is a new perspective on segmentation offers (McDonald, 2012), often it is rather a lifestyle that brings people together into coherent groups of internal homogeneity and external heterogeneity. These groups typically share the same buying and communication preferences. Thus, computer technology not only provides the ability to form social bonds and communicate (Brown et al., 2007), but also to create friendly and romantic relationships (Walther, 1996). These relationships are fundamental for the community formation on branded or non-branded topics. Communities facilitate the interactions of people with common interests (Winer, 2009) and are vital part of a brand management process (Algesheimer, Dholakia, \& Herrmann, 2005). 


\subsection{Social media and social networks defined}

Social media sites open up a new environment of conversation-based marketing communication, creating opportunities for entirely different forms of nearly instantaneous customer connections (Moriarty, Mitchell, \& Wells, 2011, p. 405). Nevertheless, to this day the significant differences exist in the perception of social media by academics and managers, largely because of the myriad of definitions generated by experts and bloggers (Bright, Kleiser, \& Grau, 2015). The most prominent feature of this is their specificity compared to the traditional content of the web that users consume similar to traditional media, however, social media allow visitors to create, modify, share and discuss content (Kietzmann, Hermkens, McCarthy, \& Silvestre, 2011; Bonsón \& Ratkai, 2013). The climate of social media offers very dynamic conditions in which technological progress is constantly bringing new opportunities for users, which is reflected in the rapid obsolescence of some general ideas, assertions, views and definitions. For these reasons, it is complicated to divide and refine definitions and in literature, we find mainly those which are strongly influenced by the current point of view of the author on the given issue.

Many definitions also describe a specific form of content and label social media as a means of sharing information in the form of text, image, sound or video. This information flows both between users and between users and brands and encourages the formation of emotional or rational motives to increase engagement with the brand (Kotler \& Keller, 2012, p. 291). The authors also see social media as a tool for listening to people's voices, building a presence on the web, and supporting other communication activities. Karlíček and Král (2011, p. 182) consider them as open interactive online applications that support the emergence of informal user networks. Informality is an important element in deciding on the choice of brand style communication. It is usual to customize the language used in social media environments, but it is always necessary to remember where the brand can go so as not to damage one of the key elements of its identity.

Interaction is seen by Steuer (1992) as the degree of the participant's share in influencing the form and content transferred in real time. Interactive communication is characterized by three basic factors: it is multi-directional, that is, two or more subjects are involved, the reactions come in a matter of seconds and are intertwined, which means that the reaction of one subject comes directly and logically from the action of another subject (Alba et al., 1997). Even though personal communication is still considered to be the most effective in persuading (Foret, 2008), Schiffman and Kanuk (2004) are of the opinion that interactive communication begins to conceal the difference between interpersonal and impersonal communication. Another important benefit of interactivity from the point of view of the marketer is that it is possible to obtain immediate reaction and information from customers (Karimova, 2011). The same is what the other side expects, therefore rapid response is a must (Shih, 2010; Moriarty et al., 2011).

Some authors draw attention to the misidentification of social networks, which are just one type of social media (Molnár, 2011; Bright et al., 2015). In their classic journal article, Kaplan and Haenlein (2010) categorised social media in a two-factor matrix. On the first axis, there is a media richness concept drawing on media richness theory (Daft \& Lengel, 1986), 
which is simply the amount of information the medium allows to be transmitted in a given time interval. On the second axis, there is self-disclosure standing for the conscious or unconscious revelation of personal information. Social networks show signs of medium media richness (compared to richer virtual social worlds and meagre blogs) and high self-disclosure (compared to low disclosure in collaborative projects like Wikipedia, content communities such as Youtube or virtual game worlds).

In consequence, new communication models and social media, in general, creates challenging requirements for few organizational changes. Not only social media managers but whole organisation must adapt to the degree of openness, interaction, and level of communication it chooses. However, Felix, Rauschnabel, and Hinsch (2017) pointed that marketing literature does not address social media challenges, such as the responsibilities of social media marketers (e.g., defining the employees who are responsible for managing social media marketing) and the role of internal and external stakeholders (e.g., defining rules and recommendations for the governance of the firm's social media presence). Effective Social media implementation requires a degree of internal collaboration and coordination that is significantly higher than that required for traditional media (Montalvo, 2011; Valos, Maplestone, Polonsky, \& Ewing, 2017).

\subsection{Social networks and communication with brands}

Providing high self-disclosure options and medium media richness social networks play indisputably the biggest role in the social media landscape. Researchers were trying to describe human behaviour in communication domain on social media. Specifically, Logan (2014) points out that the user identifies social content consumption with passive and non-active behaviour in terms of content creation. Users prefer to consume information, not to communicate. This is an important contradiction with the results of the Ungerman and Myslivcová (2014). It is not clear, therefore, whether users on social networks prefer a passive form of consumption of information or an active one, which is the basic prerequisite for the emergence of engagement.

Pereira, de Fátima Salgueiro, and Mateus (2014) combined qualitative (in-depth interview and focus group) and quantitative (questionnaire) methods. The aim of the study was to find out (1) why people are following brands on Facebook, (2) what causes people to participate in the community, and what interactions are in the community, and (3) what motivates them to share brand content on their own profile on this social network. The results showed that branding on Facebook is very popular, and the most important reasons are previous positive experience with brand $(84.8 \%)$, brand trust (83.9\%), customer experience (73.5\%), brand awareness $(64.1 \%)$ and the opportunity to participate in competitions and the availability of sales promotion offers (54.8\%). Interaction or sharing of content on the own profile is not quite common (73\% of respondents never shared branded content on their profile). Competitions and discounted sales promotion are shared by only $13.1 \%$ of respondents, event information by $10.5 \%$, product information by only $7.9 \%$. Here it is necessary to add that research has focused on sharing of a profile, which is just one of the possibilities of transferring content among users. Besides, it is very socially demanding since all content is 
distributed to most of the person friends. It is a question of whether the sharing of information to specific people through messages will be significantly higher, as this consideration is based on the assumption that the consumer can share content that is relevant to specific people in his/her social network.

Karlíček, Tomek, Hasprová, and Zamazalová (2012) examined the main reasons for use, the intensity of use, and demographic profile of the social network user. The subjects of their interest were strong Internet users. The main finding was that for these users the most important motivation for participation was the effort to be in touch with friends (85\%). In the second place, the possibility to plan activities with friends (50\%) and the third one was the possibility of organizing events (34\%). Almost the same team of scientists also published a study on the behaviour of users of this social network (Tomek, Hasprová, Zamazalová, \& Karlíček, 2012), in which he used the pyramid of engagement, demonstrating the distribution of activities from mere observation (99.1\% (86.5\%), commenting $(72.7 \%)$ and production (48.5\%) to repair $(37.7 \%)$. Their results have confirmed the fact that not all social networking users are actively creating content.

\subsection{Users engagement as key determinant of reach}

In 2010, a team around Doorn published an article on customer engagement to the brand. They characterized engagement as customer behaviour towards a brand that goes beyond purchasing and is caused by some motivational elements (Doorn et al., 2010). The customer engagement model for the brand includes behaviour like word-of-mouth, recommendations, writing reviews, helping other customers.

In the context of the introduction of the concept of engagement and its definition, research is also important for the impact of engagement on key brand elements. Dijkmans, Kerkhof, and Beukeboom (2015) conducted a study among 3531 consumers searching for the impact of engagement on corporate reputation. As it turned out, consumer engagement with the brand on social media positively affects perceived corporate reputation. Higher engagement of social media users generally leads to an intensified need to track brands and engage with them. Thus, we can talk about a relationship that was also confirmed by other authors, Leung and Bai (2013), where more active media users are more involved with the brands that operate there.

Greve (2014) examined the relationship between exposure to brand image and intended customer loyalty to the brand. He conducted an experiment in which he simulated students' involvement in the university profile (creating new university slogan) and then compared their attitudes to two questionnaires filled out by participants before and after participating in profile activities. According to his results, there is also the effect of passive engagement (including site visits and reading of other users' contributions), which also leads to increased loyalty to the brand, beyond the positive effect of active engagement (involvement in creating a slogan).

Research also showed significant relations between consumer engagement and other important business outcomes. Jahn and Kunz (2012) proved connection between fan page engagement and general brand loyalty which then leads to brand commitment, word-of-mouth 
and even brand purchase. Another study showed similar results where engagement with a Facebook fan page has positive effects on consumers' brand awareness, WOM activities and purchase intention (Hutter, Hautz, Dennhardt, \& Füller, 2013).

Another stream of knowledge emerged on the domain of brand content popularity on Facebook. Sabate, Berbegal-Mirabent, Cañabate, and Lebherz (2014) have explored a particular type of content. Specifically, it was Richness of the content in the form of images, videos and links as well as Time Frame which contained day of the post and time of publication. The study resulted in the conclusion that images are an important element of the posting strategy which significantly increase brand post popularity. Compared with a video which is, according to the authors, harder to digest. Further, time of the posts influence only number of comments and there was no evidence of other connections between the day of the week and other independent variables in the study. De Vries, Gensler, and Leeflang (2012) studied effects of vividness, information, interactivity, entertainment, position and type of comments on new likes and comments. They found evidence on the connection between vividness and number of likes and position on both new likes and comments. Brands could pin selected posts to be on the top of their wall to get more likes and comments and therefore higher engagement and reach on that particular post.

As the Web 2.0 changed the way people communicate over the internet, enabling everyone to produce and share content, social network developers had to generate a system to avoid information overload for their users. Similar to Google search, where precise mathematical algorithm selects the content of the World Wide Web to users according to their search terms, in social networks the key element of content prioritisation is engagement. Every social network company is in a pursuit of providing relevant content based on the set of criteria. It is literally not possible to provide access to all the content created; therefore, the algorithm filters the interesting content based on the previous behaviour of the users. Thus, continuous data collection and evaluation is in the heart of every social networking platform. Some of the behavioural data are then made public for companies to provide yet another feedback channel.

From the technical point of view, engagement as one of the most important components in the algorithms ensures reach - the visibility of the branded content on social networks. Companies delivering content, which generates higher engagement, can benefit from nonintrusive or interruptive forms of communication.

\section{Methods}

To develop a new communication model, the combination of two research methods was chosen. Firstly, the literature review showed patterns in current research on general communication models. Therefore, it does not provide only grounding for data collection but at the same time the sum of knowledge on communication models used in the further development stage. Secondly, the survey strategy with mainly exploratory objectives was used. The online questionnaire was developed based on previous studies (Alba et al., 1997; Algesheimer et al., 2005; Bagozzi \& Dholakia, 2006; Greve, 2014; Logan, 2014) to test the research hypothesis that there is an underlying set of factors, which can describe interrelations within 
the theorized model. The data reduction technique - an exploratory factor analysis - was used to detect variables, which together construct latent factors used to objectively describe the model.

The questionnaire was carried out with consumers who use the most popular social network Facebook. The questionnaire was in the form of an online application and was distributed through a research agency IPSOS. The population from which the sample was estimated was the internet population in the Czech Republic. We calculated the minimum sample size before the data collection process by the following equation (Kothari, 2004):

$$
n=\left(z^{2} \cdot p \cdot q\right) / e^{2}
$$

where $n$ is a sample size, $z$ is the value of the standard variation at a given confidence level, in our case it correspond to $1.96, p$ is a sample proportion $(q=1-p), e$ is an acceptable error, which is customarily set at $5 \%$ in studies with unknown standard deviation in the population (Krejcie \& Morgan, 1970). Then the $n$ calculation for $95 \%$ confidence interval, which is the most typical level, goes as follow:

$$
n=\left(\left(1.96^{2}\right) \cdot(0.5) \cdot(1-0.5)\right) / 0.05^{2}, \quad n=0.9604 / 0.0025, \quad n=384.16 .
$$

The minimum sample size for this type of study is 385 subjects. However, 481 respondents were surveyed from the research panel exceeding this minimal value by nearly 100 respondents. By placing the real number of surveyed people in the equation, we reach even lower error:

$$
\begin{gathered}
e=\sqrt{\left(z^{2} \cdot p \cdot q\right) / n}, \quad e=\sqrt{\left(\left(1.96^{2}\right) \cdot(0.5) \cdot(1-0.5)\right) / 481} \\
e=\sqrt{0.001996674}, \quad e=4.47 .
\end{gathered}
$$

We did not object data to be normally distributed since this is not one of the assumptions to conduct exploratory factor analysis. However, we observed a slight positive skew in most of the subject matter questions. The research sample met the assumptions for representativeness by having similar characteristics to the population such as age, gender and region (Table 1). The maximum deviation from internet population is in education, where university degree holders in the sample are $6.8 \%$ from the real population.

Respondents answered three types of questions. Open ended, multiple-choice and Likert scale. First, they filled their preferred brand, which they follow on Facebook to provide an overview of favourite brands among the sample. The second question was aimed at the engagement pyramid adapted from Tomek et al. (2012). The last type of question was a questionnaire consisted of 21 Likert scale statements about consumer's attitudes, behaviours and expectations regarding online communication with the brand on Facebook. Part of questions regarding attitudes toward brand communication on social networks was derived from Logan (2014). Additionally, questions about past behaviour on consumer-brand communication were extracted from two studies (Algesheimer et al., 2005; Greve, 2014). We have chosen to ask on reported past behaviour since behaviour projections can be misleading. Questions about social interactions with other fans on brand profile were derived from Bagozzi and Dholakia (2006) research about brand communities. 
Table 1. Sample structure in comparison with internet population (source: own research)

\begin{tabular}{|l|c|c|}
\hline \multicolumn{1}{|c|}{$\mathrm{n}=481$} & $\begin{array}{c}\text { Relative frequency } \\
\text { in the sample (\%) }\end{array}$ & $\begin{array}{c}\text { Internet population } \\
\text { Netmonitor (\%) }\end{array}$ \\
\hline Gender & & 51 \\
\hline Female Age & 52 & 49 \\
\hline \multicolumn{1}{|c|}{ Education } & 15.4 & 16.3 \\
\hline $15-24 \quad 22.5$ & 20.6 \\
\hline $25-34$ & 23.9 & 24.6 \\
\hline $35-44$ & 20.1 & 17.2 \\
\hline $45-54 \quad 18.1$ & 21.3 \\
\hline $55+$ & & 9.5 \\
\hline & 12.7 & 27.2 \\
\hline Elementary school & 33.5 & 39.9 \\
\hline Certificate of apprenticeship & 37.2 & 23.4 \\
\hline High school & 16.6 & \\
\hline University & & \\
\hline
\end{tabular}

Likert type questions are considered suitable for measuring attitudes and opinions (Eger \& Egerová, 2014; Malhotra \& Birks, 2007; Churchill, 1999). Seven-point Likert scale response fields ranging from completely agree to completely disagree were available for respondents. Only fully completed questionnaires were supplied by the agency.

\section{Results}

The first question in the questionnaire was open and the respondents have marked their favourite brand they follow on Facebook. The purpose of this question was to frame respondents before answering further questions regarding communication towards the selected brand. We wanted them to have their selected brand in mind during whole process of answering the survey. This question has also secondary effect. It identified few categories of brands in which the fans showed a greater degree of engagement. Therefore, the list in the table below can direct the readers to brands which provide good examples of marketing communication on social network regarding the engagement metrics. We then manually split the brands based on the product into the categories. Since respondents identified them directly, it was not possible to use the CZ-NACE classification, but a subjective assessment was necessary. Eight categories exceeding thirty responses were developed. Other brand categories, often containing single responses, were merged into the ninth category - others (Table 2).

Favourite brands consist of national as well as international companies. In the media and sports club category, the merge was no longer possible thanks to the high fragmentation. Interestingly, in e-commerce, Tchibo was selected as a favourite followed brand. Compared to other big e-commerce platforms, Tchibo seems to provide interesting content to its fans on the Facebook page. In the cosmetics category, not only retailers DM and Teta were among the choices, but there were specific cosmetics manufacturers as well. 
Table 2. Brands followed on Facebook (source: own research)

\begin{tabular}{|l|c|l|}
\hline \multicolumn{1}{|c|}{ Category name } & $\begin{array}{c}\text { Percentage from } \\
\text { total sample }\end{array}$ & \multicolumn{1}{|c|}{ Most frequent brands in category } \\
\hline $\begin{array}{l}\text { Sporting fashion and } \\
\text { equipment }\end{array}$ & 11.4 & Nike, Adidas, Puma, Reebok, Salomon \\
\hline Media $^{\star}$ & 9.8 & News, TV series, Online TV, Magazines, Radios \\
\hline Fashion & 9.6 & Bonprix, Zoot, Thao, Glami, H\&M \\
\hline Cosmetics & 8.9 & DM, Avon, Teta, AXE, Rexona \\
\hline Food and drinks & 8.5 & Red Bull, Kofola, Milka, Big Shock, Pilsner Urquell \\
\hline Electronics & 7.3 & Samsung, LG, Apple, Nvidia, Eta \\
\hline Sports club & 6.9 & Football, Ice Hockey, Floorball, Runing \\
\hline Automotive & 6.2 & Škoda, Volkswagen, Hyundai, Ford, Volvo \\
\hline Others & 31.4 & $\begin{array}{l}\text { E-commerce, Zverimex, Infant goods, Fitness, Com- } \\
\text { puter games }\end{array}$ \\
\hline Total & 100 & \\
\hline
\end{tabular}

${ }^{\star}$ Category is too fragmented to portray brands in frequency order.

\subsection{Engagement pyramid}

The second question concerned the activity described as consumer engagement toward his/ her favourite brand on Facebook. Only activities reportedly happened in a previous month to the study have been chosen (Figure 4). The most common interaction is viewing content published on the wall (displayed in consumer's newsfeed) which is done regularly by $76.7 \%$ of the respondents. This is the lowest level in the engagement pyramid. This result seems logical since such engagement does not request any demanding activity. Consumers passively and almost effortlessly view the content without their own actions. However, even this passive form of communication influences customer's loyalty (Greve, 2014).

The second most frequent activity was commenting on brand posts $(31.2 \%)$. There has been a disparity in comparison with the results of the team around Tomek et al. (2012): sharing content was at the second degree of their engagement pyramid. However, their research focused on the general user activity across social media including connections with friends and family.

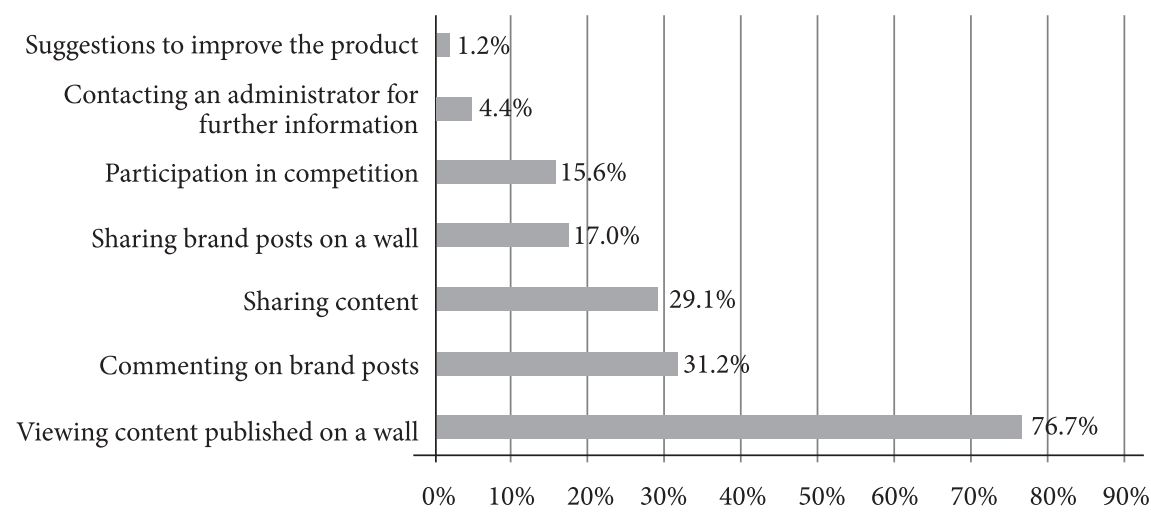

Figure 4. Consumer engagement towards their favourite brand on Facebook 
Third in frequent activities was sharing brand posts on the wall or in a group $(29.1 \%)$, which is a situation when the user spreads branded content within his or her network of friends. This activity is followed by a very similar one: sending branded content through a message $(17 \%)$ as shown in the results. That is an alternative to sharing with the difference that the content is delivered only to a selected individual who can access it.

Findings show a relatively low participation in competitions (15.6\%) which functions as sales promotion in an online environment. Contacting an administrator for further information carried only $4.4 \%$ of the respondents. This result indicates that Czech consumers do not perceive social networks as a channel of customer support yet. The least frequent activity is associated with suggestions to improve the product (1.2\%). A potential collection of innovative ideas is thus considerably unused and a general change in this approach can bring a path for market-oriented companies that want the customer to communicate on this topic.

\subsection{Exploratory factor analysis}

In order to identify the common factors in the questionnaire, the exploratory factor analysis was used. Its purpose is to find topics that affect a certain set of questions and can be labelled as underlying or latent factors. Compared to the popular cluster analysis, it serves for creating new variables that help to better understand the problem. Its main purpose is not to categorize the respondents according to the responses, but to look for factors that can simplify an understanding of complex reality.

In the first stage of data processing, all questions from the battery were subjected to the factor analysis (21 variables). The number of factors was chosen based on the Kaiser criterion (Hardy \& Bryman, 2004) and three factors with an eigenvalue greater than one were included in the analysis. Subsequently, variables whose factor loading did not exceed 0.4 (which is the generally accepted minimum factor load), were excluded from the analysis. This procedure enabled us to interpret with certainty the relevance of the question to the given factor. According to Field's recommendation (2013, p. 650), correlations of input variables were also checked to exclude multicollinearity. These correlations in no case exceeded the critical limit $\mathrm{r}=0.8$. After these adjustments and checks, 12 variables were left in the model for which the factor analysis was repeated. The number of observations was estimated to be 40 times larger than the number of variables, and therefore the generally accepted sample size rule for the factor analysis that speaks at least six times was fulfilled (Fabrigar, Wegener, MacCallum, \& Strahan, 1999).

The values of the input tests as assumptions about the suitability of the used method are the Kaiser Mayer Olkin data sampling adequacy, which determines whether it is possible to use the factor analysis at all. The value of the criterion is 0.939 (Table 3), which is above the set minimum of 0.5 recommended by Malhotra and Birks (2007). Whether there is a correlation in the data matrix is verified by Bartlet's test, which is in this case zero and indicates existing correlations.

In the following table (Table 4), the resulting solution identifies three factors, one of which is linked to four questions $(10,11,9,8)$, the other to five questions $(7,2,3,15,4)$ and the last one on three questions $(19,13,12)$. The reliability test to measure the internal 
consistency of each factor was used. Cronbach alfa for the first factor is 0.913 , for a second it is 0.862 and 0.863 for the third.

Table 3. KMO and Bartlett's test (source: own research)

\begin{tabular}{|l|l|c|}
\hline \multicolumn{2}{|l|}{ Kaiser-Meyer-Olkin Measure of Sampling Adequacy. } & .931 \\
\hline \multirow{3}{*}{ Bartlett's Test of Sphericity } & Approx. Chi-Square & 2799,461 \\
\cline { 2 - 3 } & df & 66 \\
\cline { 2 - 3 } & Sig. & .000 \\
\hline
\end{tabular}

Table 4. Pattern matrix with factors (source: own research)

\begin{tabular}{|l|c|c|c|}
\hline \multicolumn{1}{|c|}{ Pattern Matrix ${ }^{\mathrm{a}}$} & \multicolumn{3}{c|}{ Factor } \\
\cline { 2 - 4 } & 1 & 2 & 3 \\
\hline $\begin{array}{l}\text { 10. I often visit a brand profile on Facebook before purchase to } \\
\text { check how the brand communicates. }\end{array}$ & 0.885 & -0.053 & 0.015 \\
\hline $\begin{array}{l}\text { 11. I actively search for a brand on Facebook when I make a } \\
\text { purchase decision. }\end{array}$ & 0.860 & -0.058 & 0.043 \\
\hline $\begin{array}{l}\text { 9. I often visit a brand profile on Facebook before purchase to } \\
\text { check other customers' reviews. }\end{array}$ & 0.805 & 0.086 & -0.039 \\
\hline 8. I do follow a brand to have actual information. & 0.500 & 0.226 & 0.128 \\
\hline 7. I like when a profile administrator reacts to my comments. & -0.002 & 0.703 & 0.143 \\
\hline 2. It suits me to choose when to communicate with the brand. & -0.027 & 0.677 & 0.059 \\
\hline 3. I like the reversible communication with the brand. & 0.029 & 0.648 & 0.177 \\
\hline $\begin{array}{l}\text { 15. A profile administrator should know the Czech language } \\
\text { well. }\end{array}$ & 0.003 & 0.613 & -0.123 \\
\hline 4. I like when the brand is active in communication. & 0.192 & 0.602 & 0.059 \\
\hline $\begin{array}{l}\text { 19. I enjoy meeting new people who are the fans of my favou- } \\
\text { rite brand. }\end{array}$ & -0.016 & 0.006 & 0.881 \\
\hline 13. I am glad my friends know which brands I follow. & 0.102 & -0.006 & 0.713 \\
\hline $\begin{array}{l}\text { 12. Being in a company of people who like the same brand is } \\
\text { pleasant. }\end{array}$ & 0.152 & 0.222 & 0.512 \\
\hline $\begin{array}{l}\text { Extraction Method: Principal Axis Factoring. } \\
\text { Rotation Method: Oblimin with Kaiser Normalization. } \\
\text { a. Rotation converged in 7 iterations. }\end{array}$ & & & \\
\hline
\end{tabular}

In most cases, factors are named by the variables that have the strongest factor loading. In this case, however, the exploratory analysis of the questionnaire was used. Thus, questions from different sources were used and the homogeneity of the resulting groups of variables is not known in advance. Consequently, it will be better to use the approach in which the factors are named based on the thematic share.

The first factor is connected with the Facebook page being an information source for purchase decisions. The reason to follow the brand on the social network is to get information. The second factor covers questions regarding the two-way communication and its components. Therefore, the central word here is interaction. The third group of variables are leading 
to the latent factor comprising a social dimension of following brands on Facebook. This could be summed up as a community. Information, interaction and community are three latent variables were affected questions in each factor are positively skewed. The interaction factor showed the highest $(83,2 \%)$ cumulative agreement with Likert scale statements. After a huge gap, the information factor follows (60\%). Last is a community with only $54,5 \%$ of positive answers. These cumulative results reflect what users consider important and should be pursued by the social media managers.

\section{Discussion and model development}

Basic assumptions to construct the communication model suitable for social networks were discussed in the literature review section. To summarise, there have to be elements of the two-way communication with instant feedback, enhanced the customer role, different engagement levels, the openness of a company and the specified role of social media manager and communication streams within a company. From the results of the questionnaire, the information, interaction and community latent factors can be inserted into the model as they heavily influence communication on a social network. These factors simplify fragmented responses on specific questions in our survey, providing an opportunity to encompass the consumer's attitudes into coherent areas of thoughts for social media administrators and marketers. First, information in a form of content flows from brands as well as from consumers. The consumers not only visit Facebook page to have up to date information about the brand, but also to see the reactions of the page administrator and the reviews of other consumers. Consistent with a new communication paradigm described in the literature review, our data show the content created from fellow consumers has also significant value. Second, a vast majority of respondents answered positively on the interaction factor. They prefer brands with active approach and those who interact with them regularly. In other words, brands that engage make engaging consumers. Last but not least, community factor frame interconnection between the brand and the consumers and simultaneously the connection between consumers themselves. Based on these secondary and primary data, the proposed model for communication is displayed in following scheme (Figure 5).

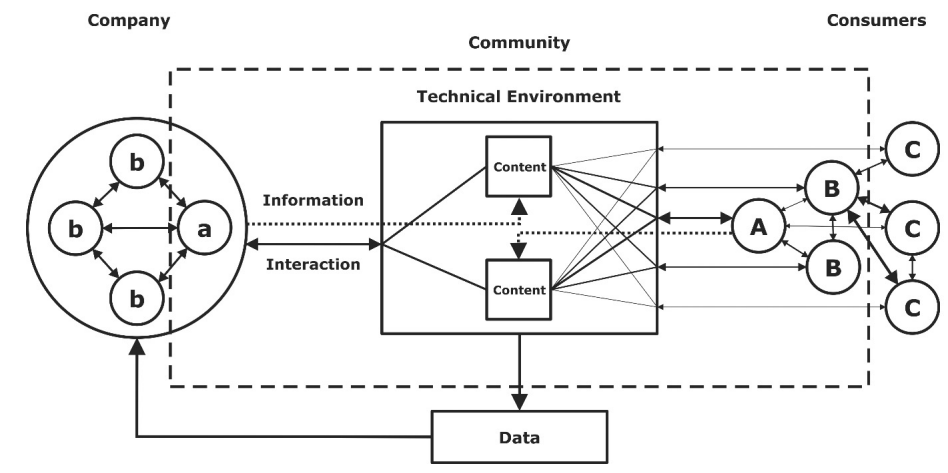

Figure 5. Marketing communication model for companies on social networks (source: own research) 
On the left side, there is a company. Specifically, the people within the organisation rounded by the circle of the company boundaries. From the company, the information flows into the technical environment of the social network in a form of content (dotted line). At the same time, the company undertakes interaction with the own and user-generated content. In the organisation, the responsible social media manager (a) performs the interaction as well as content creation. Importantly, he or she is not separated from consumers nor from other employees (b). In fact, the internal communication is a fuel for the external communication on social networks since the demand for information is continuously increasing. Timely and precise information need on the customer side increases the demand on social media manager and internal communication effectiveness.

The company is ideally integral part of its brand community. It means there are no media in the model despite the fact we traditionally refer to technical environment as social media. However, consistent with previous studies, companies themselves are producing and publishing content, therefore becoming media companies. Social networks only provide a platform to aggregate, store, sort and filter already created content. Thus, Facebook, for example, is a medium in the narrow sense.

On the other side of the scheme, there are customers. Based on the previous studies and the data from this research, the consumers form an engagement pyramid. Alternatively, to traditional architecture, the top of the pyramid is overturned to left, closer to the brand community core. Separate levels are divided by consumer engagement where most active consumers (A) generate the most interactions with a brand, create content and share branded messages. The middle level (B) is formed by consumers who do not generate the own branded content but rather interact with the brand and share information and brand messages. The last and the most numerous group (C) include all users who can be reached by the content but dominantly observe passively. By mere observational behaviour, these customers do not provide fuel for engagement and therefore are not valuable for reach development.

All the interactions with the content provide important data for the companies to manage social network profiles. By assessing how users react to different content, how they behave, what are they complaining about is a valuable source to develop a social network communication strategy. As mentioned before, filtering algorithms provide new challenges for communication.

\section{Conclusions}

Social networks are exponentially growing; however, the research of its application for marketing communication is incomparable in its tempo. In this environment, the solid theoretical framework for marketing communication on this platform is needed. Based on the paradigm shift from the mechanistic and one-way communication to the transfer of the meaning and two-way communication, we have proposed the new model for marketing communication on social networks. To ensure its accuracy the questionnaire has been the supportive tool for the new model.

The empirical findings of this study have showed categories of brands typically followed on the most widespread social network Facebook. The most favourite are sporting brands, 
media and fashion. Further, every brand has been rated by the engagement pyramid scheme to prove different behaviour of customers. Most of them only passively observe and do not engage further on a regular basis. In our model, these customers do not contribute to engagement and reach very much, therefore, are displayed out of the brand community. Lastly, the questionnaire has provided insides into attitudes and expectations of customers. The interaction is currently the main requirement from Czech Facebook users. Only the moderate majority of the respondents consider information gathering and community membership as the main element of following brands on Facebook. All three factors have been implemented in the model since they provide exploratory findings for the development stage.

The proposed scheme bears some novel aspects. Focusing specifically on the narrower concept of social networks, the content in our model is not created outside as in previous models. A social network itself provides a platform for content creation. Not only companies but also individuals are becoming media themselves. Therefore, there is no medium in our model. Consistently with the desire for interaction, the role of the two-way communication is set to be crucial in the future. The great untapped potential lies in the constructive dialogue with some expert consumers who can provide proposals for product developments. Secondly, we have expanded the physical technical environment of the social network by the abstract brand community in which not only customers but also the employees form a vital part. Lastly, the data plays an important role as a valuable tool for feedback and further analysis. The data flow from customers to companies enables managers to execute true mass individualisation. This data stream partly rejects some older theories about limitations of computer-mediated communications.

Speaking about limitations, this study has few on its own. Firstly, for engagement pyramid, the observed behaviour on social networks accessible through data mining platforms would be more suitable. Despite the fact that it would be hard to compare the data with the attitude and expectation survey like the one we have carried out. Secondly, the factor analysis as a method itself has several subjective decision-making processes such as the method of selecting a number of factors or naming the resulting factors. Further, only the most popular social network has been used so the results for other networks could provide slightly different findings. The fragmentation of favourite brands followed on Facebook has limited our ability to compare engagement results across different categories. This particular finding should inspire similar studies in terms of the cautious generalizability of the results to all business categories. Further, future research could empirically investigate the role of internal communication in social media management. In this paper, we based our conclusions about company communication streams on higher and instant information need on the consumer's side. However, specific organisational setup and readiness for new media is important research topic currently little represented in literature.

\section{Acknowledgements}

We would like to thank both anonymous reviewers for their valuable comments and feedback. 


\section{Funding}

This research was financially supported by the Student grant competition project SGS/7/2017: "Acceptance of technology from the perspective of marketing tools."

\section{Author contributions}

MK conceived the study and was responsible for the design and development of the data collection, data analysis and interpretation.

HS supervised whole process and wrote introduction.

\section{Disclosure statement}

Authors do not they have any competing financial, professional, or personal interests from other parties.

\section{References}

Alba, J., Lynch, J., Weitz, B., Janiszewski, C., Lutz, R., Sawyer, A., \& Wood, S. (1997). Interactive home shopping: consumer, retailer, and manufacturer incentives to participate in electronic marketplaces. Journal of Marketing, 61(3), 38-53. https://doi.org/10.2307/1251788

Alder, H. (2001). Mind to mind marketing: communicating with 21st-century customers. Kogan Page Publishers.

Algesheimer, R., Dholakia, U. M., \& Herrmann, A. (2005). The social influence of brand community: evidence from European car Clubs. Journal of Marketing, 69(3), 19-34. https://doi.org/10.1509/jmkg.69.3.19.66363

Bagozzi, R. P., \& Dholakia U. M. (2006). Antecedents and purchase consequences of customer participation in small group brand communities. International Journal of Research in Marketing, 23, 45-61. https://doi.org/10.1016/j.ijresmar.2006.01.005

Bonsón, E., \& Ratkai, M. (2013). A set of metrics to assess stakeholder engagement and social legitimacy on a corporate Facebook page. Online Information Review, 37(5), 787-803. https://doi.org/10.1108/OIR-03-2012-0054

Bright, L. F., Kleiser, S. B., \& Grau, S. L. (2015). Too much Facebook? An exploratory examination of social media fatigue. Computers in Human Behavior, 44, 148-155. https://doi.org/10.1016/j.chb.2014.11.048

Brown, J., Broderick, A. J., \& Lee, N. (2007). Word of mouth communication within online communities: conceptualizing the online social network. Journal of Interactive Marketing, 21(3), 2-20. https://doi.org/10.1002/dir.20082

Churchill, G. A. (1999). Marketing research: methodological foundations. Orlando: The Dryden Press.

Daft, R. L., \& Lengel, R. H. (1986). Organizational information requirements, media richness, and structural design. Management Science, 32(5), 554-571. https://doi.org/10.1287/mnsc.32.5.554

De Vries, L., Gensler, S., \& Leeflang, P. S. H. (2012). Popularity of brand posts on brand fan pages: an investigation of the effects of social media marketing. Journal of Interactive Marketing, 26(2), 83-91. https://doi.org/10.1016/j.intmar.2012.01.003 
Dijkmans, C., Kerkhof, P., \& Beukeboom, C. J. (2015). A stage to engage: social media use and corporate reputation. Tourism Management, 47, 58-67. https://doi.org/10.1016/j.tourman.2014.09.005

Doorn, J. van, Lemon, K. N., Mittal, V., Nass, S., Pick, D., Pirner, P., \& Verhoef, P. C. (2010). Customer engagement behavior: theoretical foundations and research directions. Journal of Service Research, 13(3), 253-266. https://doi.org/10.1177/1094670510375599

Eger, L. \& Egerová, D. (2014). Základy metodologie výzkumu pro studenty ekonomických oborů. Plzeň: ZČU.

Fabrigar, L. R., Wegener, D. T., MacCallum, R. C., \& Strahan, E. J. (1999). Evaluating the use of exploratory factor analysis in psychological research. Psychological Methods, 4(3), 272-299. https://doi.org/10.1037/1082-989X.4.3.272

Felix, R., Rauschnabel, P. A., \& Hinsch, C. (2017). Elements of strategic social media marketing: a holistic framework. Journal of Business Research, 70, 118-126. https://doi.org/10.1016/j.jbusres.2016.05.001

Field, A. (2013). Discovering statistics using IBM SPSS statistics (4th revised ed.). Los Angeles: SAGE.

Finne, Å., \& Grönroos, C. (2009). Rethinking marketing communication: from integrated marketing communication to relationship communication. Journal of Marketing Communications, 15(2-3), 179-195. https://doi.org/10.1080/13527260902757654

Foret, M. (2008). Marketingové komunikace. Brno: Computer Press.

Greve, G. (2014). The moderating effect of customer engagement on the brand image - brand loyalty relationship. Procedia - Social and Behavioral Sciences, 148, 203-210. https://doi.org/10.1016/j.sbspro.2014.07.035

Grönroos, C. (1994). Quo Vadis, marketing? Toward a relationship marketing paradigm. Journal of Marketing Management, 10(5), 347-360. https://doi.org/10.1080/0267257X.1994.9964283

Hardy, M. A., \& Bryman A. (2004). Handbook of data analysis. London: Sage. https://doi.org/10.4135/9781848608184

Hiltz, S. R., Johnson, K., \& Turoff, M. (1986). Experiments in group decision making communication process and outcome in face-to-face versus computerized conferences. Human Communication Research, 13(2), 225-252. https://doi.org/10.1111/j.1468-2958.1986.tb00104.x

Hoffman, D. L., \& Novak, T. P. (1996). Marketing in hypermedia computer-mediated environments: conceptual foundations. Journal of Marketing, 60(3), 50. https://doi.org/10.2307/1251841

Hutter, K., Hautz, J., Dennhardt, S., \& Füller, J. (2013). The impact of user interactions in social media on brand awareness and purchase intention: the case of MINI on Facebook. Journal of Product \& Brand Management, 22(5/6), 342-351. https://doi.org/10.1108/JPBM-05-2013-0299

Jahn, B., \& Kunz, W. (2012). How to transform consumers into fans of your brand. Journal of Service Management, 23(3), 344-361. https://doi.org/10.1108/09564231211248444

Kaplan, A. M., \& Haenlein, M. (2010). Users of the world, unite! The challenges and opportunities of social media. Business Horizons, 53(1), 59-68. https://doi.org/10.1016/j.bushor.2009.09.003

Karimova, G. Z. (2011). Interactivity and advertising communication. Journal of Media and Communication Studies, 3(5), 160-169.

Karlíček, M. \& Král, P. (2011). Marketingová komunikace. Praha: Grada.

Karlíček, M., Tomek, I., Hasprová, M., \& Zamazalová, M. (2012). Social networking sites in the Czech Republic. Management \& Marketing, 7(1), 15-28.

Kiesler, S. (1986). The hidden messages in computer networks. Harvard Business Review, 64, 46-54.

Kiesler, S., \& Sproull, L. (1992). Group decision making and communication technology. Organizational Behavior and Human Decision Processes, 52(1), 96-123.

https://doi.org/10.1016/0749-5978(92)90047-B 
Kiesler, S., Siegel, J., \& Mcguire, T. W. (1984). Social psychological aspects of computer-mediated communication. American Psychologist, 39(10), 1123-1134. https://doi.org/10.1037/0003-066X.39.10.1123

Kietzmann, J. H., Hermkens, K., McCarthy, I. P., \& Silvestre, B. S. (2011). Social media? Get serious! Understanding the functional building blocks of social media. Business Horizons, 54(3), 241-251. https://doi.org/10.1016/j.bushor.2011.01.005

Kothari, C. R. (2004). Research methodology: methods and techniques (2nd ed.). New Delhi: New Age International Publishers.

Kotler, P., \& Keller, K. L. (2012). A framework for marketing management (5th ed.). Harlow: Pearson.

Krejcie, R. V., \& Morgan, D. W. (1970). Determining sample size for research activities. Educational and Psychological Measurement, 30(3), 607-610. https://doi.org/10.1177/001316447003000308

Leung, X. Y., \& Bai, B. (2013). How motivation, opportunity, and ability impact travellers' social media involvement and revisit intention. Journal of Travel \& Tourism Marketing, 30(1-2), 58-77. https://doi.org/10.1080/10548408.2013.751211

Logan, K. (2014). Why isn't everyone doing it? A comparison of antecedents to following brands on Twitter and Facebook. Journal of Interactive Advertising, 14(2), 60-72. https://doi.org/10.1080/15252019.2014.935536

Malhotra, N., \& Birks, D. (2007). Marketing research: an applied orientation. Edinburgh: Prentice Hall.

McDonald, M. (2012). Market segmentation: how to do it and how to profit from it. Chichester: Wiley. https://doi.org/10.1002/9781119207863

Molnár, Z. (2011). Jak využít sociální sítě v podnikání. Systémová Integrace, 18(1), 134-154.

Montalvo, R. E. (2011). Social media management. International Journal of Management and Information Systems, 15(3), 91-96. https://doi.org/10.19030/ijmis.v15i3.4645

Moriarty, S. E., Mitchell, N., \& Wells, W. D. (2011). Advertising \& IMC: principles and practice (9th ed.). Boston: Prentice Hall.

NetMonitor. (2016). Trendy v návštěvnosti internetu. Praha: Sdružení pro internetový rozvoj. Retrieved from http://www.netmonitor.cz/sites/default/files/prilohy/IAC\%202016\%20-\%20NetMonitor\%20 ro\%C4\%8Denka\%202015.pdf

Pavlíček, A. (2010). Nová media a sociální sitě. Praha: Oeconomica.

Pereira, H. G., de Fátima Salgueiro, M., \& Mateus, I. (2014). Say yes to Facebook and get your customers involved! Relationships in a world of social networks. Business Horizons, 57(6), 695-702. https://doi.org/10.1016/j.bushor.2014.07.001

Perreault, W. D., Cannon, J. P., \& McCarthy, E. J. (2010). Essentials of marketing: a marketing strategy planning approach. New York: McGraw-Hill.

Sabate, F., Berbegal-Mirabent, J., Cañabate, A., \& Lebherz, P. R. (2014). Factors influencing popularity of branded content in Facebook fan pages. European Management Journal, 32(6), 1001-1011. https://doi.org/10.1016/j.emj.2014.05.001

Shannon, C. E. (1948). A mathematical theory of communication. Bell System Technical Journal, 27(3), 379-423. https://doi.org/10.1002/j.1538-7305.1948.tb01338.x

Shih, C. (2010). Vydělávejte na facebooku. Brno: Computer Press.

Schiffman, L. G., \& Kanuk, L. L. (2004). Consumer behavior (8th ed.). Prentice Hall.

Steuer, J. S. (1992). Defining virtual reality: dimensions determining telepresence. Journal of Communication, 42(4), 73-93. https://doi.org/10.1111/j.1460-2466.1992.tb00812.x

Tomek, I., Hasprová, M., Zamazalová, M., \& Karlíček, M. (2012). Behaviour of the Czech internet heavy users in online social media environment. Intellectual Economics, 6(2), 189-196. 
Ungerman, O., \& Myslivcová, S. (2014). Model of communication usable for small and medium-sized companies for the consumer communication in social media. E+M Ekonomie a Management, 17(1). https://doi.org/10.15240/tul/001/2014-1-013

Valos, M. J., Maplestone, V. L., Polonsky, M. J., \& Ewing, M. (2017). Integrating social media within an integrated marketing communication decision-making framework. Journal of Marketing Management, 33(17-18), 1522-1558. https://doi.org/10.1080/0267257X.2017.1410211

Vargo, S. L., \& Lusch, R. F. (2004). Evolving to a new dominant logic for marketing. Journal of Marketing, 68(1), 1-17. https://doi.org/10.1509/jmkg.68.1.1.24036

Varey, R. J. (2002). Marketing communication: principles and practice. London: Psychology Press. https://doi.org/10.4324/9780203466919

Walther, J. B. (1996). Computer-mediated communication: impersonal, interpersonal, and hyperpersonal interaction. Communication Research, 23(1), 3-43. https://doi.org/10.1177/009365096023001001

Winer, R. S. (2009). New communications approaches in marketing: issues and research directions. Journal of Interactive Marketing, 23(2), 108-117. https://doi.org/10.1016/j.intmar.2009.02.004 